\title{
The Temporal and Spatial Variations of Stable Isotopes in Precipitation on Different Scales in Yangtze River Basin
}

\author{
Ruiheng Meng ${ }^{* 1}$ \\ ${ }^{1}$ WLSA Shanghai Academy, 200243 Yangpu District, Shanghai, China
}

\begin{abstract}
Analysis is conducted on the temporal and spatial variations of stable isotopic composition in precipitation, using the data of IAEA/WMO sampling stations, in Yangtze river basin. The correlations between $\delta^{18} \mathrm{O}$ in precipitation and air temperature/amount of precipitation are analyzed at individual stations and in the whole valley on monthly or annual scales. There is a notable amount effect, the distinct inverse relationship between $\delta^{18} \mathrm{O}$ and precipitation, on monthly scale in the Yangtze valley and at the selected stations except Chongqing. Compared with monthly scale, the positive correlation between $\delta^{18} \mathrm{O}$ and air temperature is more marked on annual scale. The interannual variations of $\delta^{18} \mathrm{O}$ reflect the change of large-scale climate and environment, and are mainly controlled by large-scale weather conditions.
\end{abstract}

\section{Introduction}

Two stable isotopes deuterium (D) and oxygen-18 $\left({ }^{18} \mathrm{O}\right)$ occer naturally in waters. Stable isotopes of hydrogen and oxygen are an integral part of the water molecule itself, and are commonly seen as ideal tracers. To apply the stable isotope tool to the study of water cycle mechanisms, such as the mutual transformation of surface water and groundwater, groundwater replenishment, etc., the most important prerequisite is to deeply understand the composition of atmospheric precipitation isotopes, because the input item of the water cycle-atmospheric precipitation is the fundamental source of inland water resources. In the 1950s, the International Atomic Energy Agency (IAEA) and the World Meteorological Organization (WMO) jointly established the Global Network of Isotopes in Precipitation (GNIP), which was officially launched in 1961 to continuously monitor the stable isotopic composition of precipitation worldwide and it is still in progress. According to the GNIP database, China has joined the GNIP in a total of 31 sites, of which 8 belong to the Yangtze River Basin, namely Chengdu, Chongqing, Zunyi, Guiyang, Kunming, Nanjing, Wuhan, and Changsha. Past related studies in China ${ }^{[2]}$ were mostly based on fund projects and conducted local (or single-site) studies with a short period of time. It is still not clear about the relationship between long-term atmospheric precipitation isotopes, temperature and precipitation in China's inland areas. This paper uses the monitoring data in the GNIP database to analyze the long-term trend of stable isotopic changes of atmospheric precipitation in the Yangtze River Basin in China. The composition and changes of atmospheric precipitation isotope in the Yangtze River Basin at different scales were shown, which will be helpful to establish a water cycle model in the
Yangtze River Basin, clarify the characteristics of the water cycle, identify the temporal and spatial distribution of water resources, and determine the sustainable development model of water resources.

\section{Data Collection and Processing}

The sampling time, geographic location and altitude of the atmospheric precipitation at the 8 IAEA/WMO precipitation stations in the Yangtze River Basin (in Table 1) shows that the stations are unevenly distributed. Especially in the upper reaches of the basin, there is no GNIP observation station. In order to improve the accuracy of the analysis conclusions, this paper makes full use of the atmospheric precipitation isotope data of 31 stations that China has participated in the GNIP, when analyzing the spatial distribution characteristics of precipitation isotope. Environmental isotopes are expressed in thousandths relative to the Vienna-standard mean ocean water V-SMOW (Vienna-standard mean ocean water):

$$
\delta^{18} O(\%)=\left[\left(R_{\text {sample }}-R_{\mathrm{VSMOW}}\right) / R_{\mathrm{VSMOW}}\right] \times 10^{3}
$$

Where in formula (1): $\mathrm{R}$ is the isotope ratio, $\mathrm{R}=\mathrm{D} / 1 \mathrm{H}$ or ${ }^{18} \mathrm{O} /{ }^{16} \mathrm{O} ; \delta$ is the thousandth difference between the stable isotope ratio and the standard isotope ratio.

Table 1. List of basic data of 8 IAEA/WMO precipitation stations selected.

\begin{tabular}{|c|c|c|c|c|c|}
\hline $\begin{array}{c}\text { Serial } \\
\text { number }\end{array}$ & $\begin{array}{c}\text { Sampling } \\
\text { point }\end{array}$ & sampling time & latitude & longitude & Altitude/m \\
\hline 1 & Chengdu & $1986-1999$ & $30^{\circ} 40^{\prime} 12^{\prime \prime}$ & $104^{\circ} 1^{\prime} 12^{\prime \prime}$ & 506 \\
\hline 2 & Kunming & $1986-2003$ & $25^{\circ} 1^{\prime} 00^{\prime \prime}$ & $102^{\circ} 40^{\prime} 59^{\prime \prime}$ & 1892 \\
\hline 3 & Wuhan & $1986-1998$ & $30^{\circ} 37^{\prime} 12^{\prime \prime}$ & $114^{\circ} 7^{\prime} 48^{\prime \prime}$ & 23 \\
\hline
\end{tabular}




\begin{tabular}{|c|c|c|c|c|c|}
\hline 4 & $\begin{array}{c}\text { Chongqin } \\
\mathrm{g}\end{array}$ & $1992-1993$ & $29^{\circ} 37^{\prime} 12^{\prime \prime}$ & $106^{\circ} 35^{\prime} 60^{\prime \prime}$ & 192 \\
\hline 5 & Changsha & $1988-1992$ & $28^{\circ} 11^{\prime} 60^{\prime \prime}$ & $113^{\circ} 4^{\prime} 01^{\prime \prime}$ & 37 \\
\hline 6 & Zunyi & $1986-1992$ & $27^{\circ} 41^{\prime} 60^{\prime \prime}$ & $106^{\circ} 52^{\prime} 48^{\prime \prime}$ & 844 \\
\hline 7 & Guiyang & $1988-1992$ & $26^{\circ} 34^{\prime} 60^{\prime \prime}$ & $106^{\circ} 43^{\prime} 01^{\prime \prime}$ & 1071 \\
\hline 8 & Nanjing & $1987-1992$ & $32^{\circ} 10^{\prime} 48^{\prime \prime}$ & $118^{\circ} 10^{\prime} 48^{\prime \prime}$ & 26 \\
\hline
\end{tabular}

\section{The Relationship Between $\delta \mathrm{D}$ and $\delta^{18} \mathrm{O}$ in Atmospheric Precipitation in the Yangtze River Basin}

In 1961, Craig [3] discovered the linear law of global atmospheric precipitation $\delta \mathrm{D}$ and $\delta^{18} \mathrm{O}$, expressed by mathematical formula as $\delta \mathrm{D}=8 \delta^{18} \mathrm{O}+10$, which is the Global Meteoric Water Line (GMWL). However, due to the different sources of water vapor and meteorological conditions in the local circulation system in some areas, there will be significant deviations between the Local Meteoric Water Line (LMWL) and the global atmospheric water line GMWL.

$$
\delta D=7.323 \delta^{18} \mathrm{O}+5.336
$$

Equation (2) is relatively close to the global atmospheric precipitation line GMWL. Figure 1 shows that the change of stable isotopic abundance of precipitation in the Yangtze River Basin is closely related to the cause of precipitation, and is mainly affected by the type of monsoon and the source and nature of precipitation cloud clusters.

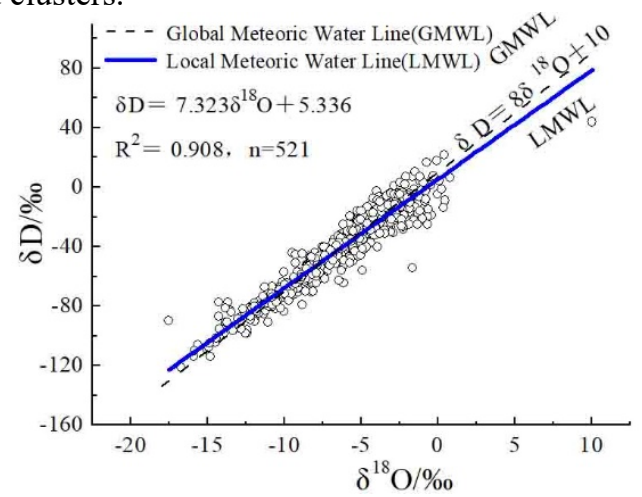

Fig. 1. the Local Meteoric Water Line in the Yangtze River.

\section{The relationship between atmospheric precipitation $\delta^{18} \mathrm{O}$ and temperature and precipitation under different time scales}

\subsection{The relationship between precipitation $\delta^{18} O$ and temperature and precipitation on a monthly scale}

The change of atmospheric precipitation $\delta^{18} \mathrm{O}$ value is a physical process of evaporation and condensation, which is related to geographical factors of temperature and precipitation, and has the characteristics of regular changes. There are temperature effects (showing a positive correlation between temperature and precipitation $\delta^{18} \mathrm{O}$ ) and precipitation effects (showing a negative correlation between precipitation and precipitation $\left.\delta^{18} \mathrm{O}\right)$, etc. ${ }^{[4,5]}$.

According to the multi-year isotope data of 8 IAEA/WMO precipitation stations in the Yangtze River Basin, the monthly precipitation $\delta^{18} \mathrm{O}$, monthly average temperature and monthly precipitation of the 8 GNIP stations and the Yangtze River Basin after calculation are shown in Table 2 and Figure 2. The change of $\delta^{18} \mathrm{O}$ is negatively correlated with the temperature on the whole. On the general trend, $\delta^{18} \mathrm{O}$ decreases with the increase of precipitation $\mathrm{P}$, indicating that atmospheric precipitation $\delta^{18} \mathrm{O}$ in the Yangtze River Basin presents a more significant precipitation effect, with greater precipitation effect than the temperature effect. The rainfall in the Yangtze River Basin is relatively high, and the air humidity is relatively high. The effect of atmospheric precipitation $\delta^{18}$ at the GNIP site can't be reflected on temperature changes, but on the effect of precipitation. The $\delta^{18} \mathrm{O}$ value of the Chongqing site increases with the increase of precipitation, with the precipitation effect masked in Chongqing, due to its extremely high temperature amid the rainy season.

Table 2. Correlation between monthly precipitation $\delta^{18} \mathrm{O}$ and monthly average temperature and monthly precipitation.

\begin{tabular}{|c|c|c|c|}
\hline & Site & $\begin{array}{c}\text { The temperature effect of } \\
\text { atmospheric precipitation } \\
\delta^{18} \mathrm{O}\end{array}$ & $\begin{array}{c}\text { The precipitation effect of } \\
\text { atmospheric precipitation } \delta^{18} \mathrm{O}\end{array}$ \\
\hline 1 & Chengdu & $\delta^{18} \mathrm{O}=-0.037 \mathrm{~T}-5.028$ & $\delta^{18} \mathrm{O}=-0.02 \mathrm{P}-3.107$ \\
\hline 2 & Kunming & $\delta^{18} \mathrm{O}=-0.488 \mathrm{~T}+0.251$ & $\delta^{18} \mathrm{O}=-0.03 \mathrm{P}-4.98$ \\
\hline 3 & Wuhan & $\delta^{18} \mathrm{O}=-0.085 \mathrm{~T}-4.421$ & $\delta^{18} \mathrm{O}=-0.01 \mathrm{P}-4.737$ \\
\hline 4 & Chongqing & $/($ Temperature data missing) & $\delta^{18} \mathrm{O}=0.012 \mathrm{P}-12.56$ \\
\hline 5 & Changsha & $\delta^{18} \mathrm{O}=-0.182 \mathrm{~T}-2.478$ & $\delta^{18} \mathrm{O}=-0.001 \mathrm{P}-5.453$ \\
\hline 6 & Zunyi & $\delta^{18} \mathrm{O}=-0.354 \mathrm{~T}-0.987$ & $\delta^{18} \mathrm{O}=-0.03 \mathrm{P}-4.01$ \\
\hline 7 & Guiyang & $\delta^{18} \mathrm{O}=-0.287 \mathrm{~T}-2.33$ & $\delta^{18} \mathrm{O}=-0.025 \mathrm{P}-4.716$ \\
\hline 8 & Nanjing & $\delta^{18} \mathrm{O}=-0.065 \mathrm{~T}-6.264$ & $\delta^{18} \mathrm{O}=-0.01 \mathrm{P}-6.132$ \\
\hline $\begin{array}{c}\text { Yangtze } \\
\text { River Basin }\end{array}$ & $\delta^{18} \mathrm{O}=-0.16 \mathrm{~T}-3.878$ & $\delta^{18} \mathrm{O}=-0.02 \mathrm{P}-4.726$ \\
\hline
\end{tabular}

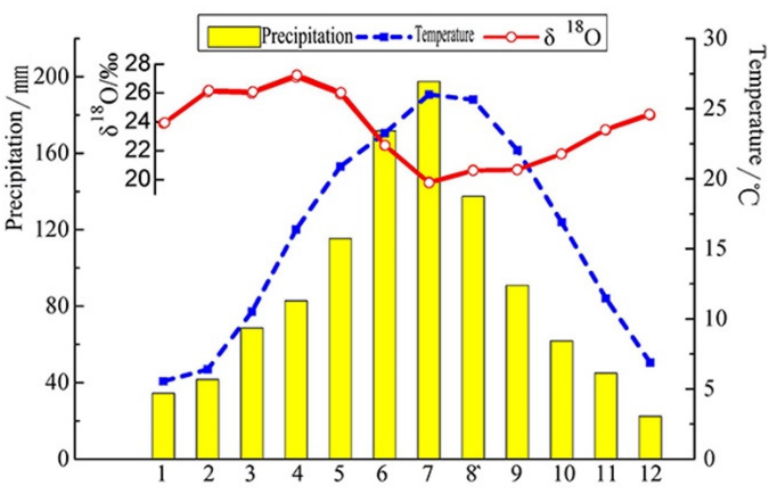

Fig. 2. The seasonal variation of monthly precipitation $\delta^{18} \mathrm{O}$ and monthly average temperature and monthly precipitation.

\subsection{The Relationship between Annual Atmospheric Precipitation $\delta^{18} \mathrm{O}$ and Temperature and Precipitation}

\subsubsection{The Relationship between Annual Declining Water $\delta^{18} \mathrm{O}$ and Temperature and Precipitation}

From the above analysis, it can be seen that on the monthly scale, except for the Chongqing site, the precipitation 
effect of atmospheric precipitation $\delta^{18} \mathrm{O}$ at the remaining seven GNIP monitoring sites is greater than the temperature effect, with the temperature effect masked. The annual weighted average atmospheric precipitation $\delta^{18} \mathrm{O}$, annual average temperature and annual precipitation, and multi-year weighted average atmospheric precipitation $\delta^{18} \mathrm{O}$, multi-year average temperature and annual average precipitation of the 7 stations with significant precipitation effects in the Yangtze River Basin are all plotted in Figure 3.

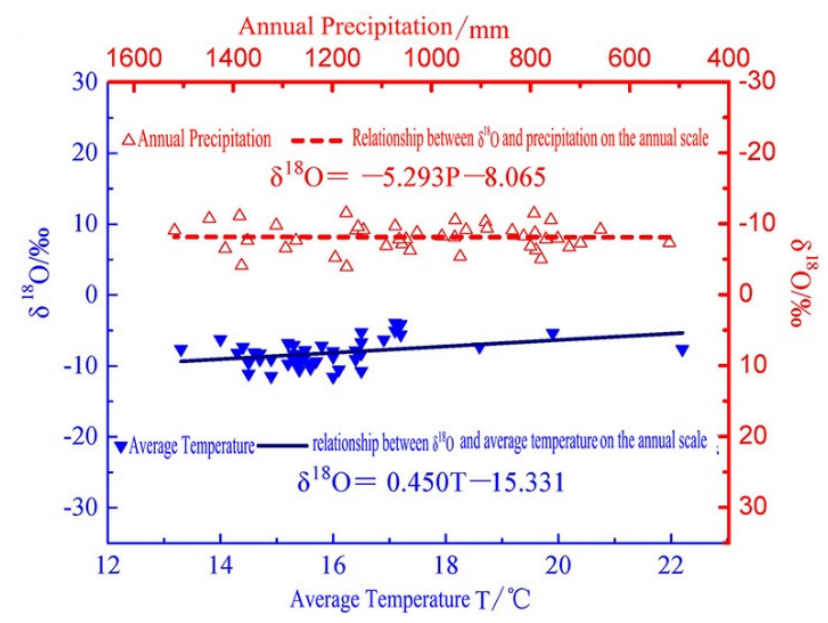

Fig. 3. The correlation between annual weighted average $\delta^{18} \mathrm{O}$ of sampling stations with precipitation effect and annual average temperature and annual precipitation.

Compared with a single station, the isotope of atmospheric precipitation in the Yangtze River Basin not only has a precipitation effect (the correlation is $\delta^{18} \mathrm{O}=$ 5.293-8.065), but also shows an interannual temperature effect (the correlation is $\delta^{18} \mathrm{O}=0.450 \mathrm{~T}-15.331$ ), which shows that the atmospheric precipitation $\delta^{18} \mathrm{O}$ is mainly subject to large-scale meteorological conditions on the interannual scale. It also reflects that environmental and meteorological conditions are large-scale spatial changes, rather than local changes. The above analysis results show that the stable isotopes of atmospheric precipitation in the Yangtze River Basin have a precipitation effect on the monthly scale. They also have a temperature effect trend, in addition to the precipitation effect on the interannual scale. Taking into account the complexity of the $\delta^{18} \mathrm{O}$ impact factors of atmospheric precipitation in the Yangtze River Basin, the temperature and precipitation changes at a single site are an important part of the changes in atmospheric precipitation $\delta^{18} \mathrm{O}$ in the basin.

\subsubsection{Changes of Annual Atmospheric Precipitation $\delta^{18} \mathrm{O}$ and Temperature and Precipitation}

In order to analyze the variation trends of the stable isotope $\delta^{18} \mathrm{O}$ of atmospheric precipitation in the Yangtze River Basin and the annual average temperature and annual precipitation over time, three GNIP sites (Zunyi, Guiyang, Kunming) with a long monitoring time were selected to analyze the trend of $\delta^{18} \mathrm{O}$ with climate change. Figure 4 shows the annual weighted average $\delta^{18} \mathrm{O}$ and annual average temperature and annual precipitation changes of 3 typical stations. The annual weighted average $\delta^{18} \mathrm{O}$ and the annual precipitation generally show a reversed change, indicating that the atmospheric precipitation isotope in the Yangtze River Basin has a precipitation effect on the annual scale. The annual weighted average $\delta^{18} \mathrm{O}$ and the annual average temperature generally show obvious simultaneous changes, indicating that the temperature effect of atmospheric precipitation $\delta^{18} \mathrm{O}$ in the Yangtze River Basin is not obvious on the monthly time scale. There is also a correlation on the annual time scale, showing the temperature effect on the annual scale. Although the monitoring time of Kunming Station is relatively long, it shows local asynchronous and anti-phase changes, mainly due to the lack of monitoring data from 1993 to 1995. Moreover, the precipitation effect of atmospheric precipitation $\delta^{18} \mathrm{O}$ at Kunming site is more obvious than that of Zunyi and Guiyang sites.

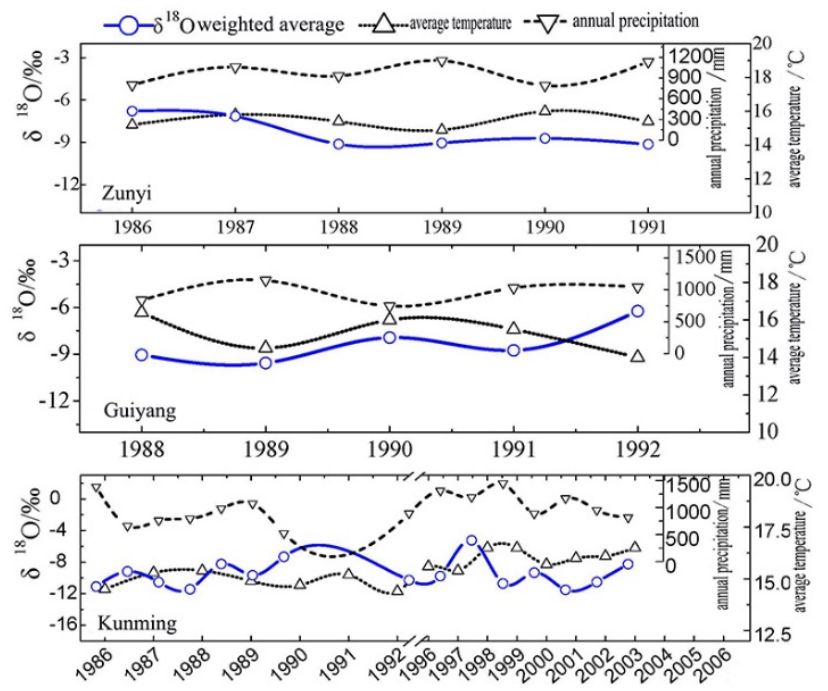

Fig. 4. The inter-annual variation of the average annual atmospheric precipitation $\delta^{18} \mathrm{O}$ and the annual average temperature at typical sites.

\section{Analysis}

Due to climatic and geographic factors, in terms of the spatial scale of the entire Yangtze River basin, the atmospheric precipitation isotope $\delta^{18} \mathrm{O}$ can reflect the geographical and regional characteristics of atmospheric precipitation and temperature to a certain extent. Due to the difference in topography of the Yangtze River Basin, the annual average temperature is higher in the east and lower in the west, higher in the south and lower in the north, and higher in the middle and lower reaches than in the upper reaches. The source area of the Yangtze River is the lowest temperature area, while the Sichuan Basin, Yunnan-Guizhou Plateau and Jinsha River Valley are closed high and low temperature central areas. Due to the vast area, complex topography and typical monsoon climate, the annual precipitation is unevenly distributed in time and space. The source area of the Yangtze River is a dry zone, while most of the watershed is a humid zone. It can be seen that the climatic diversity has caused the 
difference in the spatial distribution of $\delta^{18} \mathrm{O}$ in the atmospheric precipitation, coupled with the multi-step topography of the Yangtze River Basin, the upper reaches of the west have high terrain and large drops, and the middle and lower reaches of the central and eastern parts are low and flat, which is conducive to the deepening of the ocean airflow in the southeast direction. The effect of precipitation in China exceeds the effect of temperature to some extent.

\section{Conclusion}

The atmospheric precipitation line equation in the Yangtze River Basin is $\delta \mathrm{D}=7.323 \delta^{18} \mathrm{O}+5.336$, which is basically consistent with the global atmospheric precipitation line $\delta \mathrm{D}=8 \delta^{18} \mathrm{O}+10$.

On the spatial scale, the Yangtze River Basin shows a clear monsoon effect on the whole, affected by the topography and monsoon climate, and the temperature effect is concealed by the monsoon precipitation effect. However, the effect of atmospheric precipitation is more obvious in the middle and lower reaches than in the upper reaches and in the south of the Yangtze River than in the north of the Yangtze River. Among the 8 GNIP stations, there are 7 stations with a precipitation effect. There is a negative correlation between precipitation and precipitation $\delta^{18} \mathrm{O}$.

On the monthly time scale, the change of atmospheric precipitation $\delta^{18} \mathrm{O}$ and temperature show a negative correlation, with the precipitation effect greater than the temperature effect. As the amount of precipitation increases, the value of precipitation $\delta^{18} \mathrm{O}$ decreases. However, on an annual scale, the entire watershed not only has a precipitation effect, but also exhibits a temperature effect. Stations where the $\delta^{18} \mathrm{O}$ temperature effect is not significant on the monthly time scale exhibit temperature effects on the annual time scale. This correlation will provide an important scientific reference for further understanding of climate change and hydrological cycle laws at different time scales in the Yangtze River Basin.

The problem with the study of stable isotopes in the Yangtze River Basin is that there are few data at present, and the established perennial observation stations are relatively short in time and few in the number of stations, so comprehensive quantitative analysis is subject to certain restrictions. It is recommended to set up more stations in the entire watershed, especially in the upstream area, so as to obtain larger spatial and temporal scale observation data, to better understand the hydrological cycle process, and to study the evapotranspiration characteristics of the watershed.

\section{References}

1. Dansgard W. Stable isotopes in precipitation. Tellus, 16(4): 436-468 (1964)

2. Wang Yongsen, Chen Jiansheng, Wang Jiyang, et al. Study on the Theoretical Relationship between Hydrogen and Oxygen Stable Isotopes during Precipitation process. Advances in Water Science,
20(2): 204-208 (2009)

3. Craig $H$. Isotopic variations in meteoric waters. Science, 133: 1702-1703 (1961).

4. Vallet-Coulomb C, Gasse F Sonzogni C, et al. Seasonal evolution of the isotopic composition of atmospheric water vapor above a tropical lake: Deuterium excess and implication for water recycling. Geochim Cosmochim Acta, 72: 4661-4674 (2008).

5. Jouzel J, Merlivat L. Deuterium and oxygen-18 in precipitation: modeling of the isotope effects during snow formation. Journal of Geophysical Research, 89(D7): 11749-11757 (1984). 